\title{
An experimental study to investigate the influence of temperature and pressure on the rheological characteristics of "Glydril" water-based muds
}

\author{
Khabat M Ahmad, Zoltan Turzo, Gabriella Federer \\ Department of Petroleum Engineering, University of Miskolc, Hungary
}

Correspondence: Zoltan Turzo, Department of Petroleum Engineering, Institute of Petroleum and Natural Gas, University of Miskolc, Hungary, Email turzoz@uniOmiskolc.hu

Received: March 12, 2018 | Published: March 30, 2018

Copyright@ 2018 Ahmad et al. This is an open access article distributed under the terms of the Creative Commons Attribution License, which permits unrestricted use, distribution, and reproduction in any medium, provided the original author and source are credited.

\begin{abstract}
The global demands on oil and gas exploring deep wells are increasing quickly. Drilling at deep and ultra-deep faces a wide range of difficult challenges. One of the challenges is the negative impact on the rheological properties of the drilling fluids when exposed to high temperature high pressure conditions. To operate a drilling operation successfully, the drilling engineer must have a good estimate for the values of rheological properties of drilling fluids, such as viscosity, density, yield point, gel strength etc. In this work, an experiment was conducted on a special type of water-based mud which is called (Glydril), from ambient condition to high temperature and pressure. In this paper, we study the effects of constant pressure $(500 \mathrm{psi})$ and high temperature up to $\left(200^{\circ} \mathrm{C}\right)$.
\end{abstract}

Keywords: drilling fluid, rheological properties, yield point, plastic viscosity, gel strength

\section{Introduction}

The global growth in hydrocarbon demand is driving oil and gas industry to drill deeper reservoirs. One of the tasks in such conditions is to keep desirable rheological characteristics of the drilling muds. In deep drilling wells the rheological properties can be extremely influenced and changed by many factors. Increasing temperature and pressure are among the utmost substantial factors. It is obvious that significant numbers of oil and gas lie within the deep formations.

Temperature and pressure, however, increase with increasing depth and therefore production from such types of conditions involves several challenges to petroleum engineers in term of drilling, completion and production. Among them is the changing of the rheological properties of drilling fluid. Understanding the rheological properties of the drilling fluids under higher temperatures and pressures is vital for petroleum engineers. The success of any drilling operation, under these conditions, depends of the appropriate selection and monitoring of the drilling fluid system. The ability of a fluid to achieve a specific function is reliant on its rheological characteristics. This requires a reliable model to show how the rheological properties change with changes in temperature and pressure. Despite significant laboratory studies and research over the past decades, there is relatively little systematic understanding of how the flow behavior changes with downhole conditions. Generally, the rheological properties of the drilling fluid are influenced by many factors such as temperature, pressure, shear history and so on.

\section{Literature review}

Generally, more than 85 percent of the oil and gas industry is involved in higher temperature and higher pressure assets in some capacity and some $60 \%$ of these are expecting to put in place as HTHP program within the next few years. ${ }^{1,2}$ HTHP operation is defined as wells that have an initial reservoir temperature around $\left(150^{\circ} \mathrm{C}\right)$ and reservoir pressure close to (700 bar) or an initial reservoir pressure more than (200 bar). ${ }^{1}$ Alderman et al. ${ }^{3}$ studied rheological properties of waterbased mud under HT conditions where the temperature closes to $\left(130^{\circ} \mathrm{C}\right)$.

Amani et al. ${ }^{4}$ investigated the influence of HTHP on the viscosity of oil-based muds and water-based muds. The aforementioned studies showed that the rheological properties of the selected drilling fluids subjected to these conditions and these changes might have an undesirable influence on the drilling fluid's functions.

This laboratory work focused on investigation the rheological behavior of "Glydril," a water-based mud with different properties at HT and constant pressure. The work was completed with the help of using Fan 35A and M50 viscometer, which allow to measure the rheological properties of the selected water- based drilling fluid up to $\left(200^{\circ} \mathrm{C}\right)$ and $(500 \mathrm{psi})$. Understanding the influence of these two factors is crucial for the purpose of designing acceptable drilling fluids that can function properly in such environment. 
There are several limitations that caused developing HT/HP waterbased drilling method for mud to be a necessity. First, using oil-based muds is prohibited in many countries around the world (for example, USA, Europe) due to some environmental reasons. Secondly, due to high gas solubility in oil-based muds, there is an increase in the risk of getting kicks and hence, requires more cautious control procedures. For these reasons, formulating water-based mud capable of enduring HT/HP conditions became inevitable.

\section{Drilling fluid functions}

According to Nasser et al. ${ }^{5}$ during the drilling operation in deep reservoirs, to minimize the cost of drilling fluid and to ensure a well-organized drilling program, the rheological properties must be maintained continuously.

The high temperature conditions faced in ultra-deep oil and gas drilling environments pose key challenges for the fluids used in such environments decreases drilling fluid efficiency by reducing the rates of penetration and creates significant problems that causes to leaving behind most of the oil unrecovered. Desirable drilling fluids must offer a host of functionalities, such as:

- Control subsurface pressures, maintaining well control;

- Remove drilling cuttings from beneath the bit and circulate them to the surface;

- Maintain wellbore stability, mechanically and chemically;

- Cool and lubricate the drill string and bit;

- Allow adequate formation evaluation;
- Provide a completed wellbore that will produce hydrocarbons;

- Suspend or minimize the settling of drill cuttings or weight material when circulation is stopped, yet allow the removal of drill cuttings in the surface fluids processing system; and

- Form a low permeability, thin and tough filter cake across permeable formation.

The performance of these functions depends upon the type of formation being drilled and the various properties of the drilling fluids.

\section{Materials and methods}

Fan 35A and M50 Viscometer is used as the main viscometery device in this study (as shown in Figure 1) at the Institute of Petroleum and Natural Gas, University of Miskolc, Hungary. This system uses a rotor and bob geometry for rheology parameters measurement and applicability approved for applications in petroleum industry. The type of water-based mud chosen for this experiment has actually been used in the oil industry. The name of the mud is "Glydril," a waterbased drilling fluid. Table 1 shows the properties of the mud sample. The main object of this work is:

- To define the best rheological model for the relation between shear rate and shear stress of Glydril water-based drilling fluid.

- To identify the flow behaviour parameters of the rheological models.

- To find out the effect of HT and constant pressure on the rheological properties of water-based drilling fluid.

Table I Properties of the Glydril water-based mud

\begin{tabular}{|c|c|c|c|c|c|c|c|c|c|c|c|c|}
\hline \multirow[t]{2}{*}{$\begin{array}{l}\text { Name of } \\
\text { WBM }\end{array}$} & \multirow[t]{2}{*}{$\begin{array}{l}\text { Density/Mud } \\
\text { weight lb/gal }\end{array}$} & $\begin{array}{l}\text { PV } \\
@\end{array}$ & $\begin{array}{l}\text { PV } \\
@\end{array}$ & $\begin{array}{l}\text { PV } \\
@\end{array}$ & $\begin{array}{l}\text { PV } \\
@\end{array}$ & $\begin{array}{l}\text { PV } \\
@\end{array}$ & $\begin{array}{l}\text { YP } \\
@\end{array}$ & $\begin{array}{l}\text { YP } \\
@\end{array}$ & $\begin{array}{l}\text { YP } \\
@\end{array}$ & $\begin{array}{l}\text { YP } \\
@\end{array}$ & $\begin{array}{l}\text { YP } \\
@\end{array}$ & $\begin{array}{l}\text { Cake } \\
\text { Thickness } \\
(\mathrm{mm})\end{array}$ \\
\hline & & $25^{\circ} \mathrm{C}$ & $50^{\circ} \mathrm{C}$ & $100{ }^{\circ} \mathrm{C}$ & $150^{\circ} \mathrm{C}$ & $200^{\circ} \mathrm{C}$ & $25^{\circ} \mathrm{C}$ & $50^{\circ} \mathrm{C}$ & $100^{\circ} \mathrm{C}$ & $150^{\circ} \mathrm{C}$ & $200{ }^{\circ} \mathrm{C}$ & \\
\hline Glydril & 11.5 & 42.4 & 28 & 13.5 & 9.4 & 6.8 & 26.4 & 22.5 & 31.1 & 28.1 & 18.7 & 1.7 \\
\hline
\end{tabular}

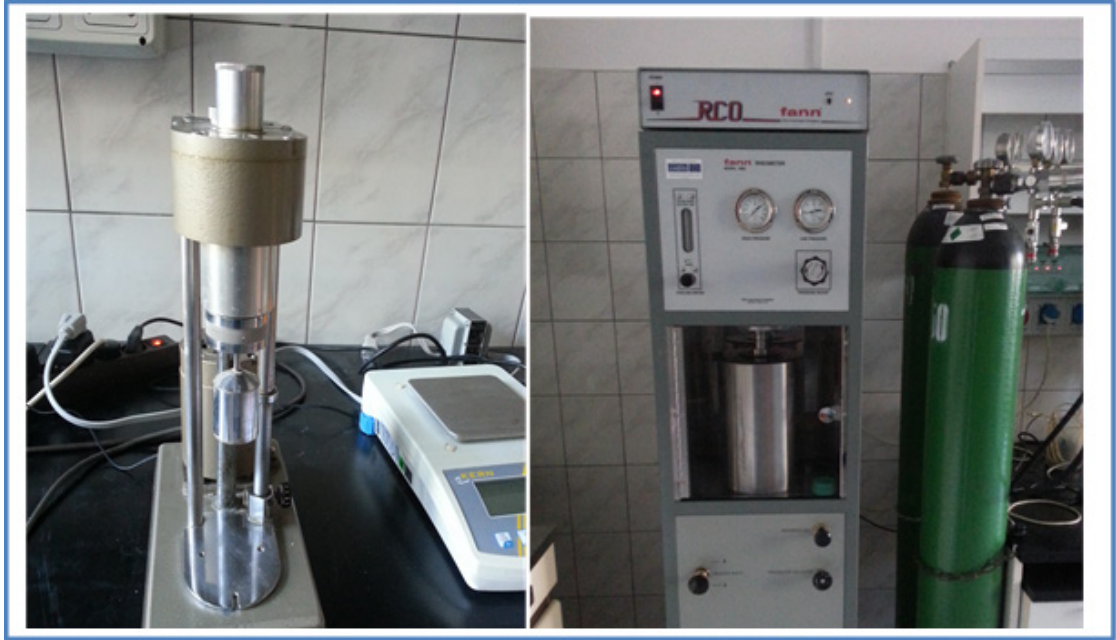

Figure I Fann 35A \& M50 Viscometer. 
Glydril mud is an enhanced-polymer, water-based system that employs polyglycol technology. Glydril delivers a high degree of shale inhibition, wellbore stability, higher temperature higher pressure fluid loss control, and lubricity. In addition, it has low toxicity, relatively fast biodegradation, improves filter cake quality and pipe wetting capability. As a result, the benefits of using Glydril mud are higher rate of penetration, fewer hole problems, fewer environmental concerns and improvement of drilling efficiency.

The first step of the experimental work started with measuring viscosity by Fan $35 \mathrm{~A}$ instrument and measurement started by using M50 Viscometer as shown in Figure 1.

In order to find the effect of specific variables, $(\mathrm{T}$ and $\mathrm{P})$, the pressure were kept constant with changing temperature from range between room temperature $\left(25^{\circ} \mathrm{C}\right)$ to $\left(200^{\circ} \mathrm{C}\right)$ with $25^{\circ} \mathrm{C}$ intervals. This allowed the analysis of the effect of temperature on viscosity of water-based drilling muds under HT/HP conditions and the pressure to be kept constant at (500 psi). During these experiments, plastic viscosity, yield point, and $10 \mathrm{sec}, 10 \mathrm{~min}$ and $30 \mathrm{~min}$ gel strengths and density were determined. The data of shear stress versus shear rate was then plotted in order to select a best rheological model to interpret the results that obtained from the laboratory measurement. Despite considerable experimental studies over the years, there is relatively little systematic understanding of how the flow behavior changes with downhole conditions. The rheology of the fluid is influenced by many factors including temperature, pressure, shear history, composition and the electrochemical character of the components and of the continuous fluid phase. ${ }^{6}$

\section{Results and discussion}

\section{Plastic viscosity and yield point (PV and YP)}

The PV and YP can be quickly calculated from the shear stress values measure at rates of 600 and $300 \mathrm{rpm}$. The PV in centipoise (cps) is calculated from the $600-\mathrm{rpm}$ dial reading $\left(\theta_{600}\right)$ minus the $300-\mathrm{rpm}$ dial reading $\left(\theta_{300}\right)$. The PV depends mainly on the concentration of solids and the viscosity of the base liquid. The YP in $\left(\mathrm{lb} / 100 \mathrm{ft}^{2}\right)$ is then calculated from the 300-rpm dial reading minus the PV. Typical six speed shear rates are taken at $600,300,200,100,6,3 \mathrm{rpm}^{7}$

$$
P V(c p s)=\theta 600-\theta 300 \quad Y P(l b / 100 s q f t)=\theta 600-P V
$$

Based on above definition, plastic viscosity represents the viscosity of mud when subjected to infinite shear rate. Figure 2 show that PV decreases with the increasing in temperature. As the temperature significantly increases up to $200^{\circ} \mathrm{C}$ the $\mathrm{PV}$ value reduces to minimum values $(\approx 6 \mathrm{cp})$. While, at $25^{\circ} \mathrm{C}$ recorder the highest level nearly (43 cp). This reduction is independent on pressure and the pressure stay constant at (500 psi). Also Figure 3 illustrates that changing in pressure with time it is almost constant. Nonetheless, the effect of pressure on plastic viscosity was more apparent at temperatures lower than $250^{\circ} \mathrm{F}^{4}$

According to Amani et al. ${ }^{4} \mathrm{YP}$ is dependent upon the surface properties of the mud solids also the volume concentration of the solids. YP might be used to evaluate the ability of a mud to lift cuttings out of the annulus. The carrying capacities of the mud depend on many factors such as annular and slip velocities, plastic viscosity, yield point and density. Therefore, measuring the viscosity and determining the yield point is a very important part of laboratory and field practice. ${ }^{8}$
Figure 4 shows that the yield point for the Glydril mud was generally decreasing with increasing temperature until a temperature $200^{\circ} \mathrm{C}$ at which the YP declined suddenly to minimum values just below 20 $\mathrm{lbf} / 100 \mathrm{ft}^{3}$, the effect of pressure is more apparent at low temperature. This is a reason to use a constant pressure in this work.

\section{PV vs Temperature}

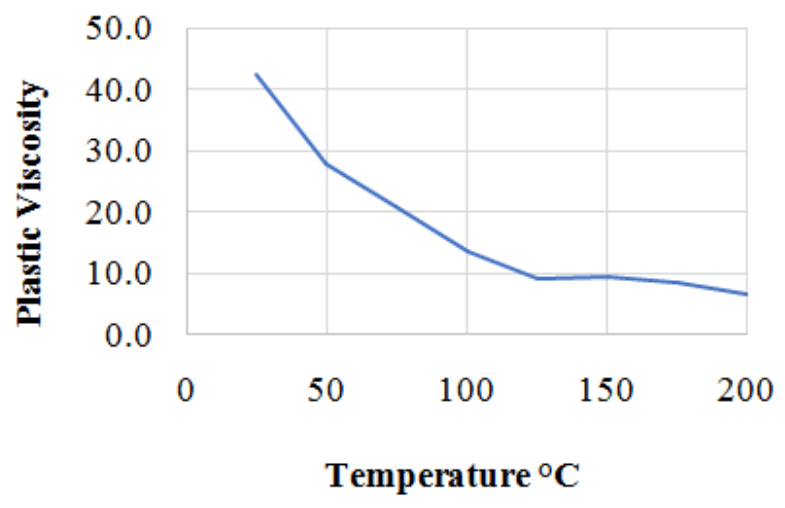

Figure 2 Plastic Viscosity vs Temperature.

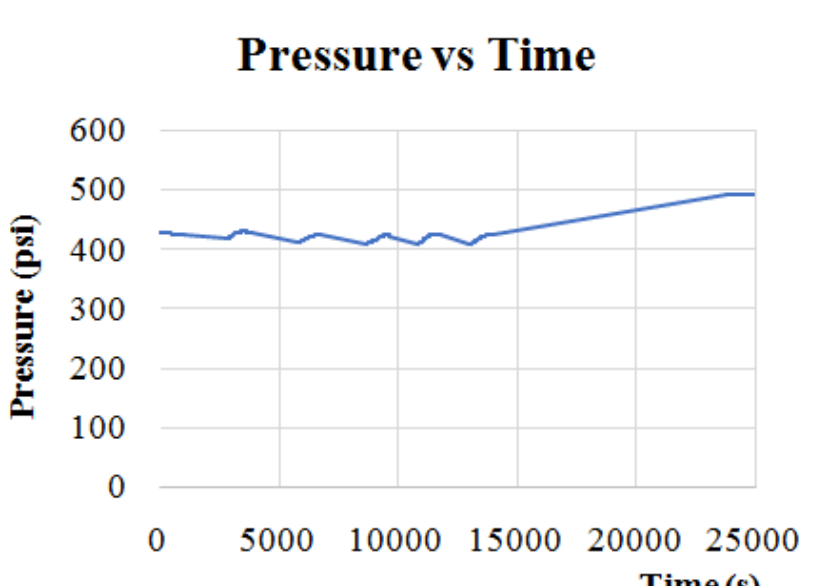

Time(s)

Figure 3 Pressure vs Time.

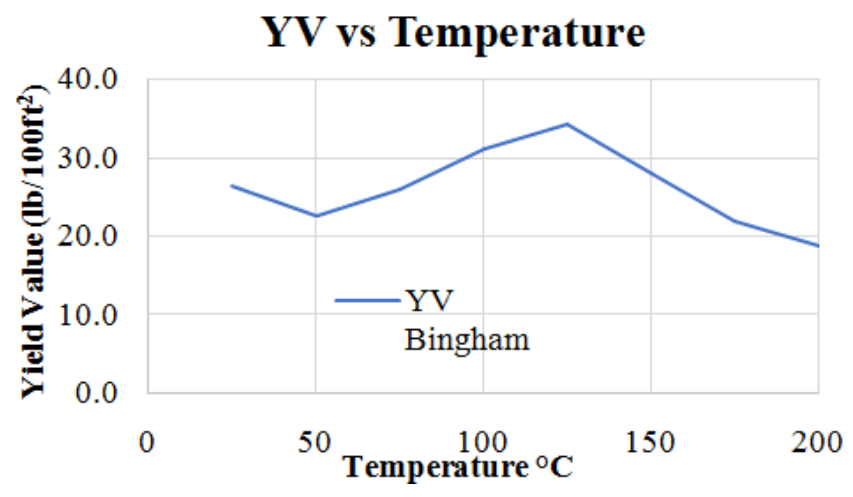

Figure 4 Yield Point vs Temperature. 


\section{Viscosity}

According to Awele ${ }^{9}$ viscosity is a flow characteristic of a drilling mud under different flow conditions. In order to predict the influences of this flow, it is important that the flow behavior of the drilling mud at numerous points of interest in the mud circulating system are known. The categories of drilling fluid are determined by the fluid behavior when it is subjected to an applied force (shear stress).

Direct indicating viscometer Fann 35A and Fann M50 in (Figure 1) is used to measure the viscosity at different shear rates to determine the rheology coefficients. The Fann $35 \mathrm{~A}$ viscometer rotates with six different speed (RPM: 600, 300, 200, 100, 6, 3) and is designed for field and lab use. The Fann M50 is a higher temperature and higher pressure viscometer, it is able to measure the rheological parameters of the drilling mud at HT, HP designed for Lab.

Figure 5 shows the viscosity values at different rotor speeds for Bingham Plastic. The graph shows that the lower the shear rate, the higher the viscosity for this model. Viscosity was decreasing with increasing temperature until a temperature value $\left(200^{\circ} \mathrm{C}\right)$ the viscosity reached at minimal values for all different rotor speeds.

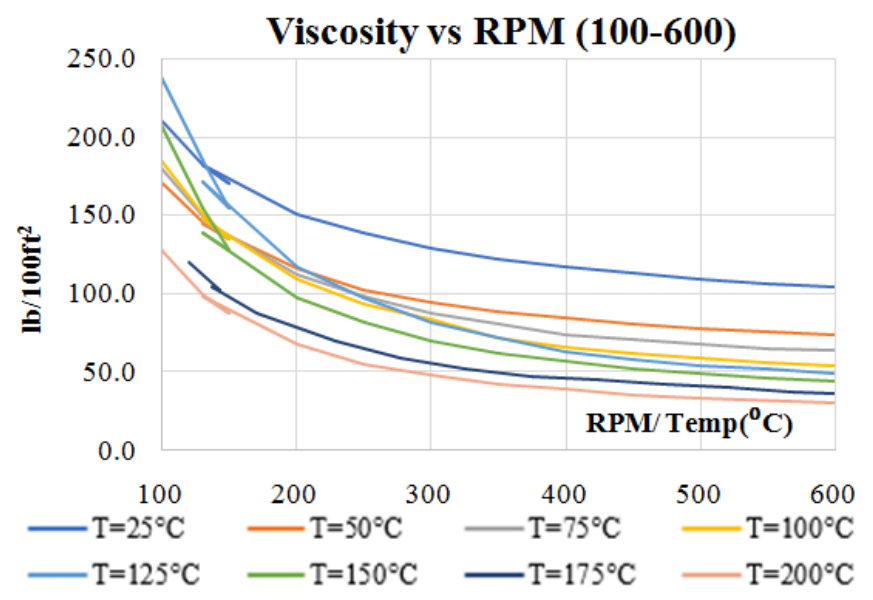

Figure 5 Viscosity vs RPM (100-600).

\section{Gel strength}

Gel strength is defined by Amani et al. ${ }^{4}$ as a "the shear stress measured at low shear rate after a mud has set quiescently for a period of time $(10-\mathrm{sec}$. and $10-\mathrm{min}$. in the standard API procedure, although measurements after 30-min. or 16-hrs may also be made." Based on previous studies, gel strengths of drilling fluid could be defined as a measure of the shearing stress required to initiate flow after static period of time and finite rate of shear, so gel strength is the ability of the drilling mud to suspend drilling cuttings and other solid additives. They are measured by observing the maximum shear stress value while slowly turning the 3-rpm setting after being static for some period of time $\left(\mathrm{lb} / 100 \mathrm{ft}^{2}\right)$. Sufficient gel strength can help suspend drill cuttings in the hole and allow them to settle out on the surface.

Gel strength measured by Fann 35A type rotational viscometer. Gel strength measured by observing the maximum shear stress value while slowly turning the 3-rpm setting after being static for some period of time. Standard values for gel strength are taken after 10 seconds, 10 minutes and 30 minutes. Table 2 presents the measured gel strength at two different times.

Table 2 Gel strength measurement

\begin{tabular}{lll}
$\begin{array}{l}\text { Gel strength at I } \min (\mathrm{lb} / \\
\left.100 \mathrm{ft}^{2}\right)\end{array}$ & $\begin{array}{l}\text { Gel strength at } 10 \mathrm{~min}(\mathrm{lb} / \\
\left.100 \mathrm{ft}^{2}\right)\end{array}$ \\
\hline First & 10.5 & 23 \\
Second & 10.5 & 23 \\
Third & 10.5 & 23 \\
\hline
\end{tabular}

\section{Filtration and filter cake}

There are many definitions of filtration both in the chemical engineering and petroleum engineering industries. Filtration or fluid loss is a relative measure of the fluid that could invade a permeable formation through deposit mud solids. Filtration is also defined by $(\text { Nasser et al.) })^{5}$ when he mentions, "Fluid loss is the measurement of filtrate passing from the drilling fluids into a porous permeable formation. Low fluid loss is a characteristic of good drilling fluids and the key to borehole integrity. The goal of good drilling fluids is to create a thin filter cake on the side of the borehole. This prevents the excessive loss of fluids into the formation." A desirable filter cake is achieved by minimizing the drill solids content of the drilling fluid and maintain the proper concentration of filtration control additives. There are many factors influencing filtration control such as thermal stability of the system, concentration, size and type of solids, and so on. ${ }^{10}$ Based on drilling fluids reference manual ${ }^{7}$ two types of filtration are considered: static and dynamic. Static filtration occurs when the fluid is not in motion in the hole. In this experiment static filtration was used and the obtained result presented in Table 3.

Table 3 Filtration measurement

\begin{tabular}{|c|c|c|c|c|c|c|c|c|c|c|c|}
\hline Time (min) & $\mathbf{I}$ & 2 & 4 & 6 & 9 & 10 & 16 & 25 & 30 & Volume $\left(\mathrm{cm}^{3}\right)$ & $\begin{array}{l}\text { Thickness of filter cake } \\
(\mathrm{mm})\end{array}$ \\
\hline Volume (drops) & 30 & 48 & 74 & 82 & 95 & 104 & 144 & 183 & 210 & 13.5 & 1.7 \\
\hline
\end{tabular}

\section{Conclusion}

Operations at higher temperature seem to be the new normal for the oil and gas industry. Drilling into the reservoirs with elevated temperature and pressure requires a fluid with stable rheological properties. In this laboratory work, the effect of higher temperature and higher on the rheological characteristics of water-based mud was studied. The following conclusions were made based on the results obtained from the tests: 
- Yield Value decreases with increasing in temperature until it reaches $25 \mathrm{lb} / 100 \mathrm{ft}^{2}$ at $50^{\circ} \mathrm{C}$ and started increasing with increases temperature slightly to $34 \mathrm{lb} / 100 \mathrm{ft}^{2}$ at $120^{\circ} \mathrm{C}$, and then after reduces to lowest point nearly $18 \mathrm{lb} / \mathrm{ft}^{2}$ at $200^{\circ} \mathrm{C}$.

- Plastic viscosity drilling mud reduces with increasing temperature and the effect of pressure was negligible especially at lower temperature.

- Viscosity decreases with increasing temperature until the temperature reaches $150^{\circ} \mathrm{C}$, and the viscosity plateaus at minimum values for all different rotor speeds. The effect of pressure on viscosity is not as dominant as the effect of the temperature.

- Gel strength was measured based on the Fann 35S viscometer at different time such as one min and $10 \mathrm{~min}$. Gel strength rises with increasing the rotation time at the same rmp.

- Bingham Plastic model gives a perfect mathematical description of water-based mud's rheology especially viscosity at higher temperature and pressure.

\section{References}

1. Loth WD and Co Ltd. Subsea engineering for the health and safety executive. HPHT Wells: Perspectives on Drilling and Completion from the Field. Sudbury: HSE Books; 1998.
2. Schlumberger Oilfield Services. Worldwide HPHT projects. https://www. slb.com/.

3. Alderman NJ, Gavignet A, Guillot D, Maitland GC. High-temperature, high-pressure rheology of water-based muds. Soc Pet Eng. 1988.

4. Amani M, Al-Jubouri M, Shadravan A. Comparative study of using oilbased mud versus water-based mud in HPHT fields. Adv Pet Explor Dev. 2012;4(2):18-27.

5. Nasser J, Jesil A, Mohiuddin T, Al Ruqeshi M, Devi G, Mohataram S. Experimental investigation of drilling fluid performance as nanoparticles. World J Nano Sci Eng. 2013;3(03):57.

6. Ibeh CS. Investigation on the effects of ultra-high pressure and temperature on the rheological properties of oil-based drilling fluids. 2010.

7. Hughes B. Drilling Fluids Reference Manual. Houston, Texas; 2006.

8. Kovacsne GF. Evaluation of drilling fluid filtration in relation with casing drilling. 2013. http://phd.lib.uni-miskolc.hu:9080/JaDoX_Portlets/ documents/document 15830 section 11876.pdf

9. Awele N. Investigation of additives on drilling mud performance with Tonder geothermal drilling as a case study. 2014. http://healthdocbox. com/Nutrition/70133260-Investigation-of-additives-on-drilling-mudperformance-with-tonder-geothermal-drilling-as-a-case-study.html.

10. Ruda TC, Bosscher PJ. Driller's Manual. Published 1990; Revised 2005. https://nda4u.com/wp-content/uploads/2016/01/DrillersManual-Chapters-1-12.pdf. 